\title{
First Case of Transulnar Approach for Angiogram (Coronary and Peripheral) in BSMMU
}

\author{
SYED ALI AHSAN, AHMED SHAFIQUL HOSSAIN, MD. HAFIZUR RAHMAN,MONJUR MAHMUD,MD ABU \\ SIDDIQUE, MUHMMAD MOBAROCK HOSSAIN \\ Department of Cardiology, Bangabandhu Sheikh Mujib Medical University, Dhaka. \\ Addressee for Corresponds: Prof Syed Ali Ahsan, Professor of Cardiology, Bangabandhu Sheikh Mujib Medical University, Dhaka. \\ E-mail: draliahsan@yahoo.com
}

\begin{abstract}
Transfemoral approach is mostly used for coronary and peripheral angiography and intervention. Transradial coronary angiography and intervention has become a popular technique due to reduced local and bleeding complications, easier post-procedural care and patient preference. In certain patients, transradial access may not be possible due to various anatomical reasons and usually, the transfemoral route is used for these patients. In a minority of patients, such as those with significant peripheral arterial disease or obesity, the transfemoral approach is challenging and is associated with an increased risk of local complications or bleeding. Transulnar arterial access, however, has recently been shown to be feasible and safe for both coronary angiography and intervention. The procedural success, advantages and complication rates for this procedure appear similar to those for the transradial approach. This is a case of transulnar artery percutaneous coronary and peripheral intervention in a patient of chronic stable angina and peripheral vascular disease.
\end{abstract}

Keywords: coronary angiography, femoral artery, radial artery, ulnar artery.

\section{Introduction:}

Transradial intervention (TRI) has become popular as an access site for percutaneous coronary intervention (PCI). Since the initial report by Kiemeneij and Laarman in 1993, ${ }^{1}$ TRI has been increasingly performed worldwide. In our country it is also increasingly done, although not as much as in other part of world. Patient preference, early mobility and discharge, ${ }^{2}$ and less bleeding complications compared to the transfemoral artery access are the reasons why some operators now perform TRI. ${ }^{3}$

In certain patients, however, TRI may not be possible due to an abnormal Allen's test or other anatomical variations. For most of these patients, the transfemoral route is used. In a minority, transfemoral access is challenging and is associated with an increased risk of bleeding such as in obese patients, or is impossible due to severe vascular disease or an aorto-iliac occlusion. In these patients, vascular access through the ulnar artery may be considered. We describe a case of transulnar artery percutaneous diagonostic angiogram in a patient with peripheral vascular disease.

\section{Case Report:}

A 60-year-old man presented with angina of one to two months duration and Claudication pain in both lower limb for five year. The cardiovascular risk factors were hypertension, dyslipidaemia and smoking. Clinical examination of the patient revealed absence of pulsations of both femoral, popliteal, and dorsalis pedis arteries.ECG was normal. Echocardiography showed normal left ventricular ejection fraction.

Although the Allen's test was normal, right ulner artery was chosen ( Fig:C) for diagonostic coronary angiography and peripheral angiography as right radial artery was clinically of a small calibre. After local subcutaneous anesthesia with $2 \%$ lidocaine, the anterior wall of the ulnar artery was punctured $1-3 \mathrm{~cm}$ proximal to the pisiform bone, using a 21 gauge needle. After the puncture, a 0.021 guidewire was inserted (Terumo Corporation, Tokyo, Japan). A 6-French (Fr) size sheath was placed (Fig: A) without difficulty was placed on the 0.021 wire through a gentle skin incision with a No. 11 surgical knife. A solution containing heparin sulfate (5.000 IU) and isosorbide mononitrate (10 mg) was injected through the introducer.

Angiography was performed with right Judkins. This showed normal epicardial coronary with dominant right side. Peripheral angiogram showed $100 \%$ block after origin of right common iliac artery. There is also $100 \%$ stenosis in left external iliac artery just after its origin. Therefore, distal arteries were not visualized in both sides after the stenotic lesions. At the end of the procedure, the arterial sheath was immediately removed with hemostasis obtained by a compressive bandage for 4 hours (Fig: D), followed by a nonocclusive pressure dressing. Recovery was uneventful, and the patient was discharged on the following day. Both the right radial and ulnar pulses were easily palpable at $7^{\text {th }}$ day follow-up. 

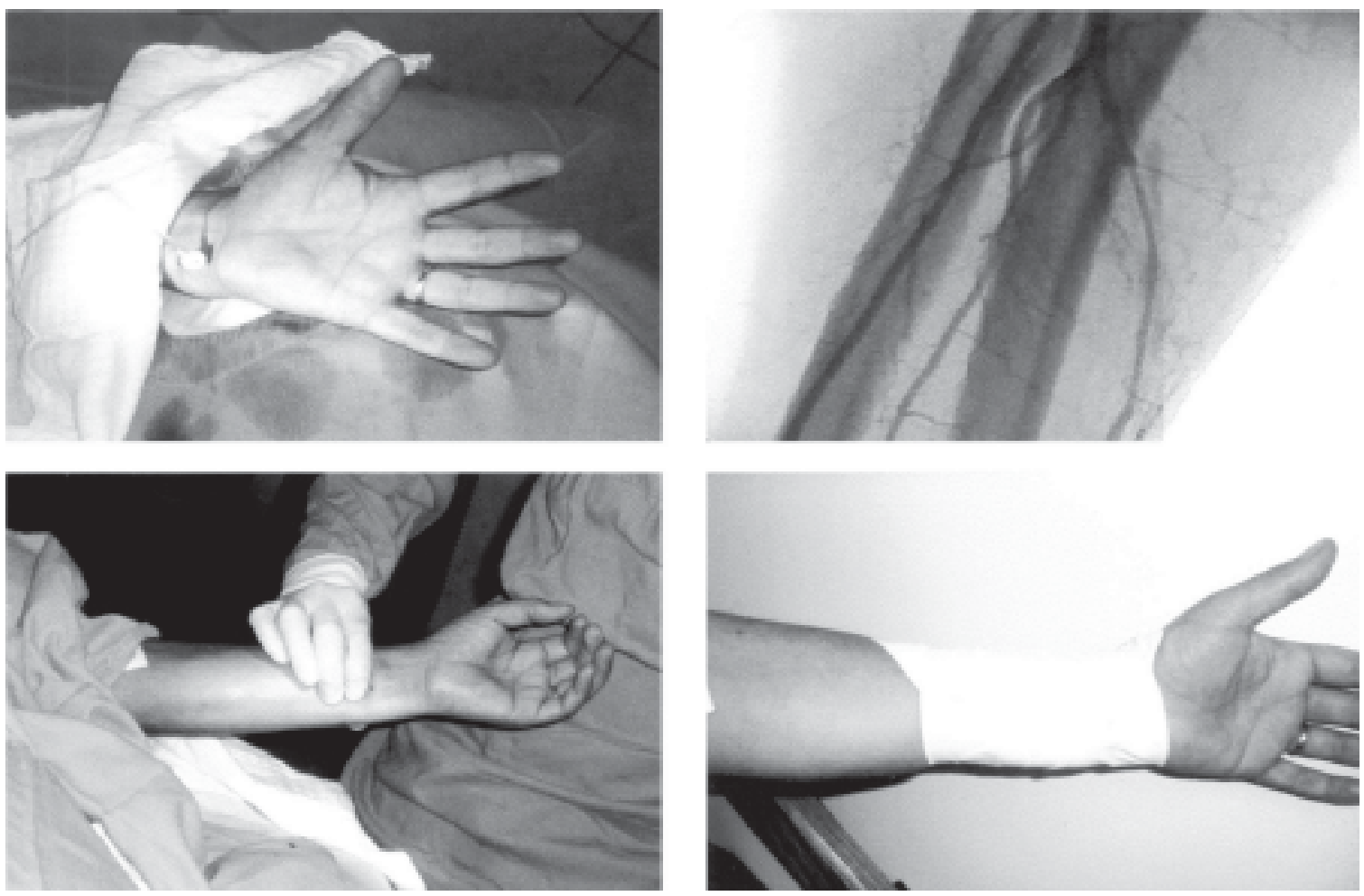

Fig.-1: A) A 6F introducer is placed after ulnar cannulation. B) Forearm angiography shows the ulnar and radial arteries. C) Manual compression of the ulnar artery. D) The compression dressing is applied for at least 4 hours after the procedure.

\section{Discussion:}

As compared to the transfemoral approach, transradial angiography and PCI have been shown to significantly reduce local access site complications $(0.3 \%$ transradial vs. $2.8 \%$ transfemoral $)^{4}$ and major bleeding $(0.05 \%$ transradial vs. $2.3 \%$ transfemoral). ${ }^{3}$ Recent data suggests that bleeding during PCI, regardless of the cause of the bleeding, can adversely affect mortality outcomes. ${ }^{5}$

This is particularly pertinent in the modern era of PCI, where potent anti-platelet and anti-thrombotic agents are routinely used. Therefore, transradial access for angiography and PCI provide an important advantage in decreasing bleeding complications. In addition, transradial access reduces the length of hospital stay and hospital costs, improves the quality of life post procedure and is strongly preferred by patients. ${ }^{2}$

For the above reasons, transradial access is now the predominant approach for coronary angiography and PCI for some operators, although this approach is associated with a learning curve and a higher rate of technical failure. ${ }^{3,6}$ Radial access is unsuitable for a significant number of patients due to an abnormal Allen's test, a small calibre artery and other anatomic anomalies. ${ }^{7}$ Previous data has shown that up to $27 \%$ of patients have a negative Allen's test, ${ }^{8}$ precluding the safe use of the transradial route. Furthermore, nearly $10 \%$ of patients in a Japanese study had anatomic variations such as excessive

tortuosity, radio-ulnar loops, stenoses and hypoplasias, although transradial PCI was successfully performed in $97 \%$ of the cohort. ${ }^{9}$

Terashima et al first reported the use of the ulnar artery as a possible alternative access site for coronary angiography in 2001.(10) Several small, single centre case series that demonstrated the feasibility and safety of transulnar angiography and PCI have since been published. ${ }^{11-13}$

One randomised study comparing the transulnar and transradial approaches has shown that both approaches had high rates of technical success (95.2\% transulnar vs. 96.2\% transradial) and a low incidence of local haematomas (5.7\% transulnar vs. $8.1 \%$ transradial), without significant differences in either route. ${ }^{14}$ No patient required a blood transfusion or vascular surgery, and none had symptoms or signs of hand ischaemia. ${ }^{14}$

The transulnar approach may therefore be an attractive alternative entry site in patients with unsuitable radial 
access, since it appears to share the same benefits as the transradial route, with no major disadvantages. This is particularly so if transfemoral access is also associated with an elevated risk of local complications, or if it is not possible due to severe peripheral arterial disease. An additional advantage in using the transulnar approach is that it can preserve the future use of the radial artery as a conduit for coronary artery bypass surgery.

The transulnar approach was ideal in our patient who had a small non-dominant radial artery, where transfemoral access was not feasible. This approach enabled angiogram to be safely performed using a 6-Fr system. There were no local bleeding complication were observed.

The patient's radial and ulnar pulses were easily palpable at 7 day post procedure. The rate of asymptomatic occlusion was reported to be $0.8 \%-5.7 \%, 13,14$ which is similar to that for asymptomatic radial artery occlusion. ${ }^{14,15}$ There were no reports of hand

ischaemia if a proper screening (normal reversed Allen's test) was conducted. Indeed, the reversed Allen's test is much more likely to be normal compared to the standard Allen's test, since the deep palmar arch (supplied by the radial artery) is complete in $95 \%$ of the patients. ${ }^{14,16}$

Due to the proximity of the ulnar nerve, which runs along the medial border of the ulnar artery, there is a risk of nerve injury during transulnar procedures. With a careful puncture using a fine gauge needle, permanent neuropraxia has not been observed, although a few patients have reported lightning-flash pain in the ulnar side of the hand. ${ }^{13}$ Due to its deeper location, access to the ulnar artery may be more challenging than the radial artery, and a learning curve has also been documented, even for experienced transradial operators. ${ }^{13}$ The only instance in which transulnar access should not be attempted is when an unsuccessful attempt at radial cannulation has just been performed during the same procedure, risking the rare event of acute occlusion of both arteries.

One might question, why an operator should choose ulnar cannulation over the radial approach. Transulnar cannulation has characteristics similar to those of the transradial approach, and a recent randomized trial suggested that the procedures were equivalent. ${ }^{13}$ Because cardiovascular disease evolves chronically, many patients need more than 1 cardiac catheterization. About 5\% will have a vascular occlusion after the transradial procedure, ${ }^{15}$ and the radial artery cannot be used thereafter as a bypass graft. The LIMA has proved to be the best vessel for use as a bypass conduit ${ }^{17}$, but the 2 nd-best conduit for use in
CABG is not clear from observational studies ${ }^{17}$. In a randomized clinical trial, Desai and coworkers observed at 1-year follow-up a worse result in vascular patency with saphenous-vein than with radial artery grafts (13.6\% vs $8.2 \% ; P=0.009)$. In addition, Kamya and co-authors showed that prior puncture of the radial artery was related to more intimal hyperplasia and reduced early graft patency.

In conclusion, transulnar arterial access for coronary and peripheral angiograpy has been shown to be feasible and safe. The procedural success, advantages and complication rates appear to be similar to those for the transradial approach. The transulnar access site can be considered as an alternative approach ${ }^{18}$, should the transradial or transfemoral route be unsuitable or unsuccessful when there is considerations for radial artery's possible use as an alternative bypass graft.

\section{References:}

1. Kiemeneij F, Laarman GJ. Percutaneous transradial artery approach for coronary stent implantation. Cathet Cardiovasc Diagn 1993; 30:173-8.

2. Cooper CJ, El-Shiekh RA, Cohen DJ, et al. Effect of transradial access on quality of life and cost of cardiac catheterisation: A randomised comparison. Am Heart J 1999; 138:430-6.

3. Jolly SS, Amlani S, Hamon M, Yusuf S, Mehta SR. Radial versus femoral access for coronary angiography or intervention and the impact on major bleeding and ischaemic events: a systematic review and meta-analysis of randomised trials. Am Heart J 2009; 157:132-40.

4. Agostoni P, Biondi-Zoccai GG, de Benedictis ML, et al. Radial versus femoral approach for percutaneous coronary diagnostic and interventional procedures; Systematic overview and metaanalysis of randomised trials. J Am Coll Cardiol 2004; 44:34956.

5. Doyle BJ, Rihal CS, Gastineau DA, Holmes DR Jr. Bleeding, blood transfusion, and increased mortality after percutaneous coronary intervention: implications for contemporary practice. J Am Coll Cardiol 2009; 53:2019-27.

6. Louvard Y, Lefèvre $\mathrm{T}$, Allain A, Morice M. Coronary angiography through the radial or the femoral approach: The CARAFE study. Catheter Cardiovasc Interv 2001; 52:181-7.

7. Valsecchi O, Vassileva A, Musumeci G, et al. Failure of transradial approach during coronary interventions: anatomic considerations. Catheter Cardiovasc Interv 2006; 67:870-8.

8. Benit E, Vranckx P, Jaspers L, et al. Frequency of a positive modified Allen's test in 1,000 consecutive patients undergoing cardiac catheterisation. Cathet Cardiovasc Diagn 1996; 38:352-4.

9. Yokoyama N, Takeshita S, Ochiai M, et al. Anatomic variations of the radial artery in patients undergoing transradial coronary intervention. Catheter Cardiovasc Interv 2000; 49:357-62. 
10. Terashima M, Meguro T, Takeda H, et al. Percutaneous ulnar artery approach for coronary angiography: a preliminary report in nine patients. Catheter Cardiovasc Interv 2001; 53:410-4.

11. Dashkoff N, Dashkoff PB, Zizzi JA Sr, Wadhwani J, Zizzi JA Jr. Ulnar artery cannulation for coronary angiography and percutaneous coronary intervention: case reports and anatomic considerations. Catheter Cardiovasc Interv 2002; 55:93-6.

12. Limbruno U, Rossini R, De Carlo M, et al. Percutaneous ulnar artery approach for primary coronary angioplasty: safety and feasibility. Catheter Cardiovasc Interv 2004; 61:56-9.

13. Aptecar E, Dupouy P, Chabane-Chaouch M, et al. Percutaneous transulnar artery approach for diagnostic and therapeutic coronary intervention. J Invasive Cardiol 2005; 17:312-7.

14. Aptecar E, Pernes JM, Chabane-Chaouch M, et al. Transulnar versus transradial artery approach for coronary angioplasty: the PCVI-CUBA study. Catheter Cardiovasc Interv 2006; 67:711-20.

15. Stella PR, Kiemeneij F, Laarman GJ, et al. Incidence and outcome of radial artery occlusion following transradial artery coronary angioplasty. Cathet Cardiovasc Diagn 1997; 40:156-8.

16. Pedro A, Marden T., Monica A,Luiz M, Andre L. Performance of Coronary Procedures through the Transulnar Access without Assessment of the Integrity of the Deep Palmar Arch. Journal of Interventional Cardiology 2008;34:1-4

17. Zacharias A, Habib RH, Schwann TA, Riordan CJ, Durham SJ, Shah A. Improved survival with radial artery versus vein conduits in coronary bypass surgery with left internal thoracic artery to left anterior descending artery grafting. Circulation 2004; 109(12):1489-96.

18. Chiam P T L, Lim V Y T. Transulnar artery approach for percutaneous coronary intervention: an alternative route in a patient with challenging transfemoral access and hypoplastic radial artery. Singapore Med J 2010; 51(5): e81 